\title{
CLINICAL AND DEMOGRAPHIC PROFILE OF PATIENTS WITH PSORIASIS AND ITS EFFECT ON THE QUALITY OF LIFE USING DERMATOLOGY QUALITY OF LIFE INDEX: A CROSS SECTIONAL STUDY
}

\author{
Sadaf Rauf ${ }^{\prime \otimes}$, Saddaf Akhtar', Farhad Ali $^{2}$
}

\begin{abstract}
OBJECTIVE: To determine clinical and demographic patterns among patients with psoriasis and their effects on quality of life (QoL) using Dermatology Quality of Life Index (DLQI).
\end{abstract}

METHODS: This cross-sectional study was conducted at Khyber Teaching Hospital Peshawar, Pakistan from September 2016 to October 2017. Consecutive sampling technique was used to select 168 patients with psoriasis. DLQI used on all patients, was split in to two groups and score $>10$ was taken as very large effect on patient's life. Data was analyzed through SPSS v. 20 software.

RESULTS: Out of total I 68 patients, I I5 (68.5\%) were female. Plaque was the commonest $(n=106 ; 63.1 \%)$ type of psoriasis followed by guttate $(n=24$; $14.3 \%)$ and palmoplantar $(n=24 ; 14.3 \%)$. Majority of psoriasis were young adults $(n=60 ; 35.7 \%)$, followed by adults $(n=56 ; 33.3 \%)$. Mean DLQI score was I0.98 \pm 4.300 . Group-I (DLQI score $=0-10)$ included $86(5 I .2 \%)$ patients and Group-2 (DLQI score > 10) included 82 (48.8\%) patients. A significant mean difference was recorded among the two groups of DLQI and age of the patient on Independent sample t-test $\{t(167)=-15.432, p=0.000\}$. In groupI, $59(51.3 \%)$ were female and $27(50.9 \%)$ were males; while in group-2, 56 $(48.7 \%)$ were females and $26(49.1 \%)$ were males.

CONCLUSION: Psoriasis is almost twice more common in female and plaque psoriasis is the commonest variety. Psoriasis has a very large effect on QoL in almost half of the patients. Impact of psoriasis on QoL of the patient is the same in both genders and is more for the erythrodermic form of psoriasis.

KEY WORDS: Psoriasis (MeSH); Dermatology Quality of Life Index (DLQI) (Non-MeSH); Dermatology (MeSH); Quality of Life (MeSH); Demographic Pattern (MeSH); Clinical pattern (Non-MeSH).

THIS ARTICLE MAY BE CITED AS: Rauf S, Akhtar S, Ali F. Clinical and demographic profile of patients with psoriasis and its effect on the quality of life using dermatology quality of life index: a cross sectional study. Khyber Med Univ J 2019; I I (4):236-9. DOI: I0.35845/kmuj.2019.19358

\section{INTRODUCTION}

$\mathrm{P}$ soriasis is a chronic inflammatory immune mediated disease with hyper-proliferation of keratinocytes in the epidermis. It has different clinical presentations with plaque variety being more common in both pediatric and adult-onset ( $74 \%$ and $79 \%$ respectively) followed by guttate
I. Medical Teaching Institution, Khyber Teaching Hospital, Peshawar, Pakistan.

2. Khyber College of Dentistry (KCD), Peshawar, Pakistan

Email『:kr.sadaf@gmail.com

Contact \# : +92-3329147630

$\begin{array}{ll}\text { Date Submitted: } & \text { May 30, 2019 } \\ \text { Date Revised: } & \text { November 22, 2019 } \\ \text { Date Accepted: } & \text { November 18, 2019 }\end{array}$

(27\%), swelling $(23 \%)$, burning $(20 \%)$ and bleeding $(20 \%){ }^{3}$

The impact of psoriasis on patients' quality of life (QoL) is similar to that of patients living with insulin-dependent diabetes, depression and angina. ${ }^{4}$ Psoriasis affects approximately $2-3 \%$ of world's population ${ }^{5}$ exhibiting bimodal age distribution i.e. childhood psoriasis occurring before 18 years and adult psoriasis that develops above 18 years. Early onset psoriasis has been shown to be more common in first degree relatives $(7 / \%)$ indicating a genetic association. ${ }^{7,8}$

As psoriasis is a lifelong disease, it affects not only the health but also the economic and social wellbeing of the patient. Therefore, to assess whether and to which extent the QoL of patient has been affected, another parameter Dermatology Quality of Life Index (DLQI) was used. DLQI ranges from 0 to 30 . The DLQI is calculated by adding the score of each question, resulting in a maximum of 30 and a minimum of 0 . The greater the score the more impaired the QoL is.'

Psoriasis affects mental health and people suffering from the disease experience significant social stigma. This study would provide a local pattern to see the trends. The study result will provide guidelines for the physicians to make evidence based judgment for the treatment considering the associated risk factor. So this study was conducted to determine the frequency and its associated factor of different types of psoriasis and its effect on the QoL using DLQI in patients with psoriasis.

\section{METHODS}

This cross-sectional was conducted at the 
TABLE I: UNIVARIATE ANALYSIS OF DIFFERENT VARIABLES

\begin{tabular}{|c|c|c|c|}
\hline Variable & Categories & Frequency & Percentage \\
\hline \multirow{6}{*}{ Gender } & Female & 115 & 68.5 \\
\hline & Male & 53 & 31.5 \\
\hline & Childhood & 13 & 7.7 \\
\hline & Adolescent & 34 & 20.2 \\
\hline & Young adult & 60 & 35.7 \\
\hline & Adult & 56 & 33.3 \\
\hline Different age groups & Elderly & 5 & 3.0 \\
\hline \multirow{2}{*}{ DLQI group } & (Group I) 0-10 score & 86 & 51.2 \\
\hline & $($ Group2) > 10.01 score & 82 & 48.8 \\
\hline \multirow{2}{*}{ Employee status } & Unemployed & $13 \mid$ & 78.0 \\
\hline & Employed & 37 & 22.0 \\
\hline \multirow{7}{*}{ Types of Psoriases } & Plaque & 106 & 63.1 \\
\hline & Guttate & 24 & 14.3 \\
\hline & Palmoplantar & 24 & 14.3 \\
\hline & Erythrodermic & 7 & 4.2 \\
\hline & Scalp & 4 & 2.4 \\
\hline & Inverse & 2 & 1.2 \\
\hline & Pustular & I & .6 \\
\hline \multirow{5}{*}{ Different infections } & RTI & 66 & 70.2 \\
\hline & UTI & 14 & 14.9 \\
\hline & GIT Infection & 5 & 5.3 \\
\hline & Skin Infection & 8 & 8.5 \\
\hline & Infectious Diseases & 1 & 1.1 \\
\hline \multirow{2}{*}{ Exposure status } & Cold/Dry Weather & 54 & 87.1 \\
\hline & Sun Exposure & 8 & 12.9 \\
\hline Mean (DLQI) Score & & \multicolumn{2}{|c|}{$10.98 \pm 4.300$} \\
\hline
\end{tabular}

DLQI = Dermatology Quality of Life Index Score, UTI = Urinary Tract Infection, RTI = Respiratory Tract Infection, GIT = Gastrointestinal Tract.

Khyber Teaching Hospital, Peshawar Pakistan and started from September 2016 to October 2017 using consecutive sampling technique. The total sample size was 171 which was calculated based on $95 \%$ confidence interval and $6 \%$ precision while taking $20 \%$ prevalence ${ }^{3}$ of burring among psoriasis patient. We selected 168 patients who consented to be interviewed through a standard questionnaire by a dermatologist. The questionnaire contained two parts; the sociodemographic data and Dermatology Quality of Life Index Score. The mean DLQI score was split in to two groups. Score more than 10 was taken as very large effect on patient's life by their skin disease. Data was analyzed through SPSS v.20 software. Categorical variables were presented in the form of frequency and percentages while continuous variable were presented in the form of means and standard deviation. Independent sample ttest was applied in both groups based on DLQI with age. $P$ value of $\leq 0.05$ was considered significant. Data was then analyzed with SPSS v.20 software.

\section{RESULTS}

Out of total 168 patients with psoriasis, Most of the participants were females II 5 (68.5\%) compare to males (31.5\%). The mean age of the participants were $31.95 \pm 17.04$. Then age was categorized in to two age groups. Young adult population, age from 21 to 35 years, was more reported with psoriasis $60(35.7 \%)$ among all other age group. The mean DLQI score was $10.98 \pm 4$.3.Among the different presentation of psoriasis, the most common was plaque psoriasis 106 $(63.1 \%)$ followed by guttate psoriasis 24 (14.3\%). Similarly the most common of rare forms of psoriasis was erythrodermic psoriasis $(4.2 \%)$ followed by scalp psoriasis $(2.4 \%)$ [Table I].

Risk factor like sun exposure, and cold/dry weather were evaluated among the two groups (Table II). Among the group I, cold/dry weather was most common risk factor $33(61.1 \%)$ while the sun exposure was the common risk factor in group 2, $07(87.5 \%)$. Similarly different infections were evaluated with DLQI. The presence of infectious diseases was reported in group 2. Comparing these DLQI groups with occupation status, $54.1 \%$ employed participants were reported in group 2 .

Independent sample t-test was applied to know the mean differences among the two groups of DLQI and age of the patient to test the null hypothesis that there is no significant difference between means of age among two groups of DLQI, a significant $\mathrm{p}$-value was recorded which failed to accept the null hypothesis and a significant mean difference was recorded $\{t(167)=-15.432, p=0.000\}$.

\section{DISCUSSION}

In our study, very large effect of psoriasis was observed on the QoL of about $51.2 \%$ patients. Psoriasis causes great physical, emotional and social burden. ${ }^{10-12} \mathrm{QoL}$, in general, is often significantly impaired. ${ }^{13-15}$ WHO global report on psoriasis shows that the greatest burden of psoriasis disease occurred in the 50-69 years of age group and that psoriasis caused slightly higher DALYs burden (disability adjusted life years) in adult males than in adult female up to 75 years of age. ${ }^{16}$ In our study the most affected population was the young adult population, age 21 years to 35 years. The reason might be possible that the WHO study was conducted globally while in our scenario most of our working individual belongs to the age of 21 to 35 years and they are exposed to many different environmental exposures. Another study conducted by Hagg, et al. ${ }^{17}$ in Sweden to investigate the sex differences in the severity of psoriasis using the gold standard of severity measurement, the Psoriasis Area and Severity Index (PASI). They found that female had statistically significantly lower median PASI scores than male ${ }^{17}$ which were consistent across all ages. This study shows that female have less severe psoriasis compared with male area and severity wise. An Iranian study on psoriasis shows that the negative impact on patient's QoL was higher for male than female. ${ }^{18}$ In the present study, however, frequency was greater in female but the difference in mean DLQI for male and female was statistically insignificant. This was consistent with the study of Azura, et al. who found no differences in mean DLQI between male and female. This demonstrates that gender has no role in 
TABLE II: DISTRIBUTION OF DLQI CATEGORIES WITH DIFFERENT INDEPENDENT VARIABLES

\begin{tabular}{|c|c|c|c|}
\hline \multirow[b]{2}{*}{ Variable } & \multirow[b]{2}{*}{ Categories } & \multicolumn{2}{|c|}{ DLQI categories } \\
\hline & & $\begin{array}{l}\text { 0-10 score } \\
\text { GROUPI }\end{array}$ & $\begin{array}{c}\text { More than } 10 \\
\text { score GROUP2 }\end{array}$ \\
\hline \multirow{2}{*}{ Gender } & Female & $59(51.3 \%)$ & $56(48.7 \%)$ \\
\hline & Male & $27(50.9 \%)$ & $26(49.1 \%)$ \\
\hline \multirow{5}{*}{ Age categories } & Childhood & $9(69.2 \%)$ & $4(30.8 \%)$ \\
\hline & Adolescent & $19(55.9 \%)$ & $15(44.1 \%)$ \\
\hline & Young adult & $26(43.3 \%)$ & $34(56.7 \%)$ \\
\hline & Adult & $29(51.8 \%)$ & $27(48.2 \%)$ \\
\hline & Elderly & $3(60.0 \%)$ & $2(40.0 \%)$ \\
\hline \multirow{2}{*}{ Risk factor } & Cold/Dry Weather & $33(61.1 \%)$ & $21(38.9 \%)$ \\
\hline & Sun exposure & 01 (12.5\%) & 07 (87.5\%) \\
\hline \multirow{5}{*}{ Different infection } & RTI & $38(57.6 \%)$ & $28(42.4 \%)$ \\
\hline & UTI & $6(42.9 \%)$ & $8(57.1 \%)$ \\
\hline & GIT Infection & $6(42.9 \%)$ & $8(57.1 \%)$ \\
\hline & Skin Infection & $3(37.5 \%)$ & $5(62.5 \%)$ \\
\hline & Infectious disease & $0(0.0 \%)$ & I (I00.0\%) \\
\hline \multirow{7}{*}{ Type of Psoriasis } & Plaque & $54(50.9 \%)$ & $52(49.1 \%)$ \\
\hline & Guttate & $12(50.0 \%$ & $12(50.0 \%)$ \\
\hline & Sebo Psoriasis & $0(0.0 \%$ & I (I00.0\%) \\
\hline & Erythrodermic & $\mathrm{I}(\mathrm{I} 4.3 \%$ & $6(85.7 \%)$ \\
\hline & Palmoplantar & $14(58.3 \%$ & $10(41.7 \%)$ \\
\hline & Scalp & $04(100.0 \%$ & $00(0.0 \%)$ \\
\hline & Inverse & $01(50.0 \%$ & $01(50.0 \%$ \\
\hline \multirow{2}{*}{ Occupation } & Unemployed & $69(52.7 \%)$ & $62(47.3 \%)$ \\
\hline & Employed & $17(45.9 \%)$ & $20(54.1 \%)$ \\
\hline
\end{tabular}

the incidence of psoriasis.

The Iranian's study also showed that the impact on QoL increased with the number of areas involved by the disease. The highest negative impact on QoL was observed when the neck or hands were involved, and the lowest when the groin was involved. The mean DLQI in the present study was much higher in erythrodermic psoriasis than other types of psoriasis. In the present study, Plaque psoriasis was the commonest followed by guttate. The same distribution was found by Azura, et al. who carried out study to evaluate the epidemiology and clinical characteristics of patients with psoriasis in Malaysia. They found that most common clinical presentation was chronic plaque psoriasis, followed by guttate psoriasis, erythrodermic psoriasis, and pustular psoriasis. ${ }^{7}$ In a similar fashion, a crosssectional, observational study was conducted at the Dermatology Department of the Clinical Hospital of the University of Chile applying an epidemiological and QoL-related survey to psoriatic patients. The most frequent disease subtype was plaque psoriasis, followed by guttatiform psoriasis ${ }^{19}$ which is inconsistent with our study. This was first kind of study to show the risk factors associated with psoriasis in our local setup. It was, however out of the scope of this study to discuss further association between risk factors and psoriasis or any relationship between systemic diseases and psoriasis however, respiratory tract infections, urinary tract infections and gastrointestinal tract infections were seen in patients with psoriasis. Sample size was calculated on proper software of WHO sample size calculator. In the present study, however, there were some limitations like, this was a hospital based study which cannot be generalized on the local community, sampling technique was weak and sample size was small. There is an immense need for more epidemiological studies to improve understanding of the disease burden in the community and updating population awareness and health policies. Further study is also needed to show association between PASI and DLQI.

\section{CONCLUSION}

The psoriasis is almost two times more common in female as compared to male. Adult population is more affected and plaque psoriasis is the commonest variety. Psoriasis has a very large effect on QoL in almost half of the patients. Impact of psoriasis on QoL of the patient is the same in both genders and is more for the erythrodermic form of psoriasis.

\section{ACKNOWLEDGEMENT}

We acknowledge the untiring efforts of $\mathrm{Dr}$ Imran Ali towards this study.

\section{REFERENCES}

I. Tollefson MM, Crowson CS, McEvoy MT, Maradit Kremers H. Incidence of psoriasis in children: a population based study. J Am Acad Dermatol 2010 June;62(6):979-87. DOI: 10.1016/j.jaad.2009.07.029.

2. Mercy K, Kwasny M, Cordoro KM, Menter A, Tom WL, Korman N, et al. Clinical manifestations of pediatric psoriasis: results of a multicenter study in the United States. Pediatr Dermatol 2013;30(4):424-8. DOI: 10.1 II I/pde. 12072.

3. Dubertret L, Mrowietz U, Ranki A, van de Kerkhof PC, Chimenti S, Lotti $\mathrm{T}$, et al. European patient perspectives on the impact of psoriasis: the EUROPSO patient membership survey. B J D e rmatol 2006;।55(4):729-36. DOI: |0. I | II/j. |365-2|33.2006.07405.x.

4. Grozdev I, Kast D, Cao L, Carlson D, Pujari P, Schmotzer B, et al. Physical and mental impact of psoriasis severity as measured by the compact Short Form-12 Health Survey (SF-I2) quality of life tool. J Invest Dermatol 20। $2 ; 132(4)$ : II।I-6. DOI: I0. I038/jid.20I I.427.

5. Braun-Falco O, Pelwig G, Wolff $\mathrm{HH}$, Landthaler M. Burdorf WHC BraunFalco's Dermatology. Springer-Verlag Berlin Heidelberg; 2009.

6. Bhutto AM. Childhood psoriasis: A review of literature. J Pak Assoc Derma 20I I;2I(3): 190-97.

7. Kormeili T, Lowe NJ, Yamauchi PS. Psoriasis: Immunopathogenesis and 
evolving immunomodulators and systemic therapies; US experiences. $\mathrm{Br} J$ Dermatol 2004;15I(I): 3-15. DOI: $10.1111 /$ j. $1365-2133.2004$. 06009.x.

8. Busch AL, Landau JM, Moody MN. Pediatric psoriasis. Skin Ther Lett 2012;17(I):5-7.

9. Finlay AY, Khan GK. Dermatology Life Quality Index (DLQI)—a simple practical measure for routine clinical use. Clin Exp Dermatol 1994;19(3): 210-6. DOI: I0.1III/j.1365-2230. |994.tb0| |67.x.

10. Fuji RK, Mould JF, Tang B, Brandt H, Pomerantz D, Chapnick J, et al. Burden of disease in patients with diagnosed psoriasis in Brazil: results from $201 \mathrm{I}$ national health and wellness survey (NHWS). Value Health 20I2;I5(4):AI07. DOI: 10. I0I6/j.jval.20I2.03.580.

II. Stern RS, Nijsten T, Feldman SR, Margolis DJ, Rolstad T. Psoriasis is common, carries a substantial burden even when not extensive, and is associated with widespread treatment dissatisfaction. J Investig $\mathrm{D}$ e rmatol Sym P P c 2004;9(2):|36-9. DOI: 10.1046/ j. I087-0024.2003.09I02.x.
12. Kimball $A B$, Jacobson $C$, Weiss $S$, Vreeland MG, Wu Y. The psychosocial burden of psoriasis. Am J Clin Dermatol 2005;6(6): 383-92. DOI: I0.2I65/ 00I2807|-20050606000005.

13. De Korte J, Sprangers MA, Mombers FM, Bos JD. Quality of life in patients with psoriasis: a systematic literature review. J Investig Dermatol Symp Proc 2004;9(2): |40-7. DOI: 10.1046/ j. I087-0024.2003.09। I0.x.

14. Zachariae H, Zachariae R, Blomqvist $\mathrm{K}$, Davidsson S, Molin L, Mørk C, et al. Quality of life and prevalence of arthritis reported by 5,795 members of the Nordic Psoriasis Associations. Data from the Nordic Quality of Life Study. Acta Derm Venereol 2002;82 (2): I08-I3. DOI: I0.1080/000 I5550252948| 30 .

I5. Krueger G, Koo J, Lebwohl M, Menter A, Stern RS, Rolstad T. The impact of psoriasis on quality of life: results of a 1998 National Psoriasis Foundation patient-membership survey. Arch Dermatol 200 I; 37 (3):280-84. DOI: 10-1001/pubs. Arch Dermatol.-ISSN0003-987x-I37-3-dst0024.

16. Institute for Health Metrics and Evaluation. The Global Burden of
Disease: Generating Evidence, Guiding Policy. Seattle, WA: IHME, 2013. [Cited on: May 29, 2019]. Available from URL: https://www. healthdata.org/sites/default/files/files/ policy_report/2013/GBD_Generatin gEvidence/IHME_GBD_GeneratingE vidence_FullReport.pdf.

17. Hagg D, Sundstrom A, Eriksson M, Schmitt-Egenolf M. Severity $f$ Psoriasis Between Men and Women: A Study of Clinical Outcome Measure Psoriasis Area and Severity Index (PSAI) in 5438 Swedish Register Patients. Am J Clin Dermatol 20I7; I8(4):583-90. DOI: 10.1007/s40257-017-0274-0.

18. Mohd-Affandi A, Khan I, Ngah-Saaya N. Epidemiology and clinical Features of Adult Patients with Psoriasis in Malaysia: 10 Years Review from the Malaysian Psoriasis Registry (20072016). Dermatol Res Pract 20I8;20|8:437|47|I. DOI: 10.1155/2018/437|47|

19. Valenzuela F, Silva P, Valdés MP, Papp K. Epidemiology and quality of life of patients with psoriasis in Chile. Actas Dermosifiliogr 20II; I02(10): 810-16. DOI: 10.1016/j.ad.20II.03.022.

\section{AUTHORS' CONTRIBUTIONS}

Following authors have made substantial contributions to the manuscript as under:

SR: Study design, acquisition of data, drafting the manuscript, critical review, final approval of the version to be published

SA: Conception, critical review, final approval of the version to be published

FA: Analysis and interpretation of data, drafting the manuscript, final approval of the version to be published

Authors agree to be accountable for all aspects of the work in ensuring that questions related to the accuracy or integrity of any part of the work are appropriately investigated and resolved.

CONFLICT OF INTEREST

Authors declared no conflict of interest GRANT SUPPORT AND FINANCIAL DISCLOSURE NIL

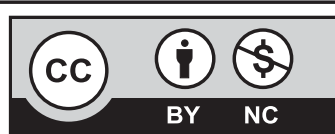

This is an Open Access article distributed under the terms of the Creative Commons Attribution-Non Commercial 2.0 Generic License. 